\title{
LAS MUJERES EN LOS ORÍGENES DE TORREFORTA
}

\author{
As mulheres nas origens da Torreforta
}

\author{
Enric Olartecoechea Camprubí
}

\begin{abstract}
CUADRADA, C.; GUTIÉRREZ, E. (2014). Les dones als orígens de Torreforta. Tarragona: Centre d'Estudis Històrics i Socials Guillem Oliver del Camp de Tarragona.
\end{abstract}

En un contexto académico, a la hora de publicar un escrito, suelen resolverse con sobrada satisfacción las preguntas que interrogan por el qué y el cómo. Sin embargo, pese a la ampulosa retórica científica u objetivista, rara vez me complacen las respuestas al por qué y al para qué, y mucho menos cómo se inscribe el quién en estas cuestiones. Hemos aprendido a alejarnos del objeto de estudio para garantizar una objetividad y rigurosidad determinadas, o, dicho de otra manera, asumimos como deseable la negación del sujeto que escribe.

Les dones als orígens de Torreforta ${ }^{1}$ demuestra que es posible -o incluso deseable- acercarnos a una realidad sin renunciar a la subjetividad ni, con ella, a la rigurosidad. Echando mano de Haraway, cuanto más se sitúe fenomenológicamente el sujeto en su propio texto, más fácil resulta entender aquello que describe ${ }^{2}$ y permite a la lectora o lector simpatizar o disidir con las ideas de la obra sin tener que decapar las toneladas de retórica objetiva que dificultan una lectura profunda y comprometida.

* Universidad Autónoma de Barcelona. Institut Miquel Tarradel. Espanha.

1 En adelante : "Les dones...".

2 Para profundizar sobre el concepto de objetividad que teoriza Haraway, véase el capítulo 7, "Conocimientos situados: la cuestión científica en el feminismo y el privilegio de la perspectiva parcial", de la obra Ciencia, cyborgs y mujeres. 
El primer capítulo es una exhaustiva defensa de un posicionamiento feminista poco convencional en contextos académicos e incluso minoritario dentro del propio movimiento feminista. Por eso son necesarias treinta páginas para hablar del método y la metodología utilizada; para justificar la inclusión del sujeto dentro de la propia explicación sin convertirlo en alguien ajeno a la realidad explicada; para entender que hablar de algo implica un compromiso, por eso este capítulo puede considerarse un referente para aquellas personas que deseen lanzarse a una aventura similar desde las ciencias sociales. Desgraciadamente, pese al notable esfuerzo de las escritoras, todavía es difícil deshacerse de la retórica académica al uso, y en algunos capítulos posteriores este afán queda reducido a algunas líneas finales. Con todo, esfuerzos como éste tienen el mérito de traducir unos ideales, que a menudo se extinguen en disertaciones eruditas -imprescindibles pero insuficientes-, hacia campos de la investigación aplicada.

Les dones... nos acerca a la historia de un asentamiento obrero, situado en las afueras de Tarragona, fruto de la migración forzada Ya en las primeras páginas descubrimos cómo la invisibilización de las mujeres, un fenómeno tan habitual en la historiografía, ha impedido revelaciones tan sorprendentes como saber que la migración a Cataluña que tuvo lugar entre los años 40 y 50, fue eminentemente femenina y producto de la represión franquista. Con posterioridad, el grueso de la migración pasa a ser masculina, movidos esta vez por causas fundamentalmente económicas. Pero la segunda ola migratoria parece eclipsar la primera y la historiografía actual todavía no lo reconoce. Aunque su presencia en la documentación escrita tardara en llegar, por ser habitualmente ciega al trabajo informal y doméstico, al estraperlo, a la prostitución o a la confección de ropa desde casa, son precisamente los relatos de sus protagonistas los que nos revelan una realidad mucho más extendida y significativa de lo que se creía.

Otra tendencia historiográfica habitual consiste en centrarse en los núcleos de poder o en los colectivos visibles y organizados según estructuras convencionales, con el fin de explicar los cambios sociales de mayor relevancia. Lejos de tratarse de grupos sociales desorganizados e incivilizados, este libro nos demuestra que estos asentamientos produjeron altísimos niveles de organización, muchos de ellos sostenidos por mujeres, las cuales llevaron a cabo una larga reivindicación que perseguía unas condiciones de vida dignas. Movilizaciones, todas ellas, que con el tiempo 
iban a influir mucho más allá de sus confines. El ejemplo de Torreforta es, probablemente, un caso extensible a muchos otros barrios ${ }^{3}$ poco estudiados de Cataluña y de la península en general.

A continuación, el libro nos invita a profundizar sobre el substrato religioso que impregnaba la sociedad de la época. Sin desmerecer el papel de la Iglesia en la construcción del miedo, la garantía de control social y el lavado de cerebro, hubo excepciones, a menudo personalistas, que se tradujeron en curas y monjas más o menos de izquierdas que apoyaron movilizaciones y protegieron a parte de la ciudadanía de la represión franquista. Como se demuestra en el tercer capítulo, estos eclesiásticos provenían de la influencia de un movimiento obrero que tuvo su apogeo europeo en los años '40. La HOAC (Hermandad Obrera de Acción Católica) ${ }^{4}$, en España, o la Joventut Obrera Catòlica entre otras fueron, tal vez, algunos de sus mejores exponentes del movimiento católico de izquierdas en tiempos franquistas.

Conseguimos hacer un grupo bastante grande de chicas [de la $\mathrm{HOAC]}$ [...] cada una explicaba los problemas que tenía en su fábrica, si habia visto alguna injusticia, todo se llevaba a la reflexión. [...] al final me despidieron una vez que pudieron [...]. Aunque no era de ningún partido político, sólo por eso ya me llamaban comunista [Les dones..., p. 112].

Como era evidente -y no por ello debía de dejarse de lado-, la educación se encargó de inculcar los valores más recalcitrantes de la religión católica y los principios fascistas de régimen. El siguiente capítulo nos recuerda cuán profunda fue la cicatriz católica sobre el cuerpo y la mentalidad (muy especialmente la femenina). Y, no obstante, se aleja asimismo de las posiciones victimizadas de las mujeres para rescatar los ejercicios creativos y de resistencia que, dentro de este estrecho y vigilante escenario, permitieron descubrir, conocer y desear más allá de sus angostos límites.

"Cada cosa en su sitio. Y el de la mujer no es el foro, ni el taller, ni la fábrica, sino el hogar, cuidado de la casa y de los hijos, y de los hábitos

3 Aunque en un sentido estricto, a estos núcleos poblados no puede llamárselos barrios, sino asentamientos, chabolismo, etc., uso deliberadamente este término para poner en evidencia el esfuerzo de sus pobladores y pobladoras por convertirlo en un lugar digno y habitable.

4 Como demuestra el libro, muchos de los integrantes más conocidos de CCOO pertenecieron a la HOAC. 
primeros y fundamentales de la vida volitiva y poniendo en los ocios del marido una suave lumbre de espiritualidad y amor." [Les dones..., p. 139]. Y si no bastaba con inculcar un buen manual de instrucciones de género, en alusión al concepto católico de familia, el régimen no dudó en echar mano de la biología. En lo que parece una clara recuperación de la vieja frenología, que justificaba las capacidades o los déficits según parámetros anatómicos, el ABC publicó, en 1943, que el estudio de volúmenes y manuales suponía "un trabajo mental para ellas excesivo, que roba riego sanguíneo a regiones orgánicas fundamentales para su porvenir de mujeres." [Les dones..., p. 144]. Se trata de un capítulo que nos acerca a la vivencia de nuestras madres o abuelas por medio de la memoria viva de las mujeres que miran hoy, sin miedo, su experiencia del ayer.

Que las mujeres han trabajado durante toda la historia de la humanidad parece ser una afirmación dudosa si hemos de ceñirnos a los manuales de historia. Ya sea por el olvido del trabajo doméstico, del cuidado de los hijos, ya por no constar en ningún registro (trabajo informal, en negro, prostitución, etc.), a menudo su papel en la economía ha sido despreciado cuando no ignorado por completo. Suele ovillarse tras la naturalizada capacidad reproductiva y cuidadora, como si de un instinto natural se tratara, parecido al parpadeo involuntario o a la respiración semivoluntaria, algo que hoy en día el discurso cotidiano revive en la forma de "instinto maternal". El quinto capítulo nos muestra, pieza por pieza, capa a capa, cómo se naturalizan las construcciones sociales de género y cómo se insertan en la escala de valores sociales.

Esta parte no solamente repasa las principales críticas feministas a las concepciones dominantes de la economía y el trabajo, sino que los va entrelazando con los testimonios de las mujeres de Torreforta, cuya percepción corrobora la invisibilidad del trabajo femenino al tiempo que lo visibiliza. "Yo nunca he trabajado" afirma Emilia, la misma mujer que nos cuenta que "cuando vino a Bonavista no había agua, en Torreforta había pero mala, salada, la teníamos que comprar. Íbamos a la fuente, daba muchos viajes porque la tenía cerca, allá nos encontrábamos todas. En la Canonja había unas albercas para lavar y nos íbamos allí a lavar, con mi cesto y algunas de mis hijas" [Les dones..., p. 183]. "Ayudé a mi madre con todos mis hermanos pequeños, que tuve muchos. No he tenido niñez nunca." [Les dones..., p. 191] 
El capítulo concluye con un posicionamiento no inocente de todo lo dicho con anterioridad: la autora deja de un lado el pudor y se despoja de cualquier retórica superflua para decirnos cuáles son sus intenciones, cuál su punto de partida epistemológico y cuál su lucha a lo largo de todos estos años como profesora universitaria y feminista. De haber acudido a la peligrosa neutralidad para hablar de estos temas, hubiésemos sido testigos de un ejercicio de arrogancia desmedida, y de otra forma de naturalizar lo social.

Las últimas páginas nos invitan a recorrer las luchas de las mujeres. Los colectivos feministas Cau de Llunes y Causa Morada son los responsables de guiarnos por este último capítulo, antes de desembocar en la conclusión. Que hayan sido unos colectivos de esta naturaleza y no cualquier otra persona o colectivo quienes lo escriban, hace justicia a la epistemología feminista defendida en las primeras páginas del libro. Conocer los tímidos pasos que acercaron a las primeras mujeres al feminismo durante los años 70 es un ejercicio genealógico del propio colectivo, un esfuerzo por recuperar la memoria que hizo posible las luchas actuales. ¿Acaso los colectivos feministas de hoy, entre los que participo, serían posibles sin el esfuerzo de todas aquellas mujeres que levantaron la voz en esas difíciles décadas?

La fuerza que adquirieron las asociaciones vecinales, surgidas a raíz de aquella solidaridad femenina que tenía que contar los céntimos para comprar el pan o el medicamento, que trataba de educar a los hijos e hijas y mantener el hogar en condiciones óptimas, se convirtió en un agente con voz propia y capaz de llevar las reivindicaciones que solo una sensibilidad labrada a fuerza de velar por las condiciones de vida podía elaborar. En cierto sentido podría colegirse que fueron esas mujeres las que exigieron en primera instancia una cobertura social mínima, como extensión de su trabajo y política domésticas dentro del hogar, una garantía de bienestar que luego adornarían las medallas que colgarían de las camisas de los líderes sindicales. Poco tardaron los padres de familia en adueñarse de las primeras asociaciones vecinales, conocidas por algunas de sus protagonistas como la Associació de mestresses de casa ${ }^{5}$, después de descubrir la fuerza que éstas obtuvieron en el terreno político. Berta, uno de los testimonios orales, podría ser más lata pero no más clara: "ellas volvieron a casa, y ellos agarraron las riendas de toda la reivindicación del barrio" [Les dones..., p. 236].

5 Puede traducirse como: "Asociación de amas de casa". 
Para aquellas personas que no tienen miedo a reconocer en las pequeñas vidas las grandes historias, para quienes tengan el valor de mirar con espíritu crítico lo cotidiano y no asumir las relaciones de poder o la desigualdad como fenómenos irremediables, este libro puede ser una buena herramienta. Aunque en algunas ocasiones, la lectora encontrará descompensada o repetitiva la contextualización de la época que ocupa las primeras páginas de cada capítulo, no podrá negar que se trata de un serio esfuerzo contra el ninguneo de la Historia: "Hacer historia" ya huele a sangre azul, a famoso o a militar; con libros así, hacer historia, nos devuelve la capacidad y la alegría de transformar el mundo sin naufragar en la utopía.

Recebido em 23 de setembro de 2014. Aprovado em 14 de novembro de 2014. 